\title{
The Dilemma of Learning Phrasal Verbs among EFL Learners
}

\author{
Salman A. Al Nasarat \\ Language Center, Al Hussein Bin Tala University, Jordan
}

Corresponding Author: Salman A. Al Nasarat, E-mail: salman.nasarat@yahoo.com

\section{ARTICLE INFO}

Article history

Received: December 25, 2017

Accepted: March 07, 2018

Published: April 30, 2018

Volume: 9 Issue: 2

Advance access: March 2018

Conflicts of interest: None

Funding: None

\section{Key words:}

Translation,

Phrasal Verbs,

Interpreting, EFL,

Jordanian Students

\begin{abstract}
This study was designed to examine difficulties in interpreting English phrasal verbs (PVs) that individual college student of English face during their academic career. Interpretation is an apparent obstacle that Jordanian English students encounter as they learn language systematically. The learners being investigated were divided into two groups including regular students of English language and literature and non-majoring English students who study communication skills in English at Al Hussein Bin Talal University. Basically, the present study attempted to investigate students' background level and performance to identify the source of weakness in interpreting PVs either orally or based on written texts. The findings would shed light on translating inability and more significantly on interpreting strategies while students work out the meaning of spoken or written PVs combinations. The overall score obtained by students in the designed test resulted in a plausible explanation for this learning problem and should help for a better course design and instruction as well as effective classroom teaching and curricula.
\end{abstract}

\section{INTRODUCTION}

Translation is described as the process of translating words or texts from one language into another. Translation is seen as a transformation of ideas, meaning, messages, or feelings from the source language (SL) into the target language (TL). Halliday (1976) considers translation to be: "the total process and relationship of equivalence between two languages". We shall differentiate, nevertheless, between "translating" (written language) and "interpreting" (spoken word). Translation, therefore, is the action of interpretation of the meaning of a text.

Newmark (1988) mentioned that in order to be able to translate a certain text, one has to understand it and analyze it first. Translation theories should have criteria to be followed by the translator. The translator should translate the text according to the writer's intention not according to his/ her view about subject, and he/she must take into consideration several things such as age, sex, and class of writer.

Linguistically, interpreting and translation quite related tasks. Seldom are they conducted by the same person. The difference in skills, training, experience and even language capacity are so fundamental that not many specialists can do both successfully. Apparently, the difference between interpreting and translation is that the interpreter performs actual meaning orally, whereas a translator deals with written word. Both interpreting and translation combine a mutual intelligibility of two or more languages. One important issue regarding interpreting is dealing with English two-part verbs. A phrasal verb is a combination of a verb and a preposition, a verb and an adverb, or both. These combinations are not only part of the basic structure of utterances, but also are having a complete meaningful unit. Phrasal verbs are sometimes also referred to as 'compound verb', 'verb-adverb combination', or 'verb-particle construction (VPC.)' Once we will refer to this compound verb in the abbreviated form PVs.

PVs present a wide range of variability both in terms of syntax and semantics. Thus, they are challenging for students learning English as a second language (Sinclair, 1989). A verb followed by a particle may show syntactic ambiguity (see [my cousin] off, eat [up to five bananas]). This affects how they are to be clarified, interpreted, and translated appropriately. Fletcher (2005) points out that PVs can also be used in all types of written text, even in formal ones, when they are useful to deliver the message of the author.

One study on hardness of translating PVs from English to French by Carlos Ramisch and Laurent Besacier and Alexander Kobzar (2013) claimed that PVs have been proved to be rather 'colloquial' or 'informal 'and more appropriate to spoken English than written" (Sinclair, 1989, p. iv), PVs are convincing and can be seen in all aspects of language.

Kleinmann (1977) believes that "avoidance" indicates that learners can recognize structure, but cannot use them 
freely. Failure to use a structure or word that is unknown to the learners is a clue of ignorance, not of learning difficulty. Levenston (1971), on the other hand, claimed that avoidance phenomena provide an explanation for L1 interference with L2 learning assuming that they have stylistic effect on the learner's L2.

However, PVs are particularly common in the English language and a PV often has a meaning which is quite different from the original verb. For instance, the phrasal verb "came across" can be replaced with "found by chance" as seen below:

- $\quad$ Phrasal Verb: I came across the camp while I was walking up the mountain.

- Single Verb: The digital watch was found by chance early this morning.

Therefore, the purpose of this study is to investigate the linguistic capabilities and learners' strategies employed by L2 Jordanian students of English when dealing with spoken texts, written exercise, or organized classroom material test and trying to interpret PVs involved in based on linguistic capacity, language translating and interpreting backgrounds. This part of English (separable and inseparable PVs) is not given the attention it deserves- it is not clear enough when a preposition, or which preposition is needed and what rules are there to govern its use. Since PVs found in Arabic language have a completely different form, structure and function, the current study would familiarize students of English with importance of this aspect of language and of mechanics available to help master this essential part of spoken and written English. This individual study will allow us to directly and critically analyze the learners' performance in dealing with both spoken and written texts. This will allow the researcher to explore a new aspect of learning spoken and written English that he has not studied in my other classes and help to focus his major upon a specific area.

So, to achieve the purposes of this study the researcher attempts to answer the following questions:

1. Does gender, major or academic year play a vital part the skills of PVs interpretation when it comes to language use?

2. How can students analyze the content of spoken texts where PVs are addressed through listening?

3. What difficulties that PVs involve when L2 learners interpret from SL to TL in writing tasks?

4. How do L2 students identify the meaning of PVs in sentence completion based on interpreting knowledge and linguistic performance?

Here we attempt to recognize how Jordanian Arabic college students work out the interpreting mechanism to clarify the meaning of PVs. First, this study enlightens the relation between linguistics and interpretation. Second, it indicates how interpreting difficulty leads to misunderstanding to the readers in the target language. That is, the obstacles Arab students encounter in interpreting VPs from English into Arabic. To expose the kind of interpretation problems Arab English-major undergraduates face when translating, this study uses a test designed for this purpose and administered to a sample of 37 students of English language and literature and 20 advanced students of different majors who are taking communication skills in English as an optional course.

\section{THE DILEMMA OF PVS LEARNERS}

There are various translation problems, not all of which have received much attention. Interpreting as well as translation are essentially procedure of paraphrasing or reformation of text. That is, the interpreter listens to a speaker, perceives the whole meaning of the spoken utterance, and then paraphrases it based on knowledge of the target language. However, it is the same when someone cannot explain an idea to a listener if he or she does not comprehend that idea entirely. You will not be able to translate or interpret it without understanding what is being said. According to Halliday and Hasan (1976), "the word text is used in linguistics to refer to any passage of whatever length that does form a unified whole." Since not all texts have the same core structure and the same properties, it is the context in which they appear that will determine to their unique differences.

We assume that most students are likely to come up against different interpreting. Based on the above argument, there is inevitably a degree of oversimplification as most VPs are not informal, slang, or improper for educated speech. Most VPs are acceptable at all levels of spoken and written English. In fact, there is no alternative to the PV- there is no other way to say it (Hart, 1999). An interpreter should be able to translate without dictionaries' help or other extra materials. Interpreters must obtain good hearing skills, especially for simultaneous interpreting. Sometimes they need to focus for a long time and memorize groups of words spoken continuously.

PVs are frequently used in informal English speakers produce them unconsciously. In fact, many native and non-native users of PVs are unaware of what they mean or do through speech! Unluckily, PVs may have influence language interpretation negatively, as the meaning of two or three words would be changed into a single unit which may have a very different formula and semantic meaning. Moreover, a grammatical problem may also be referred to avoidance; the same verb can be attached to different preposition and it can be intransitive (i.e. the plane is taking off) or transitive (i.e. he handed over the money), active (i.e. I took my shoes off) or passive (i.e. the match was put off).

\section{PHRASAL VERBS}

A number of past studies were conducted on the translation of PVs and avoidance. A limited number of case studies concerned the issue of VPs interpretation, but rather focused on grammatical or translation problems and avoidance by L2 learners. Carl W. Hart (1999) claimed that PVs are difficult to teach because there are no rules that govern when or which a preposition is needed to combine a certain verb.

Dagut and Laufer (1985) identified Hebrew learners' ignorance of English PVs. They assume that L1 Hebrew learners' would avoid PVs construction. To explain this phenomenon clearly, Dagut and Laufer (1985) conducted three tests including (multiple choice, verb translation and 
memorization) on a number of Hebrew learners of English. They investigated the frequency of avoidance appeared in PV types such as (literal, figurative, or completive). The findings of the study revealed the Hebrew learners' preference of oneword verb over PVs as a result of avoidance behavior.

Liao and Fukuya (2004) tested seventy intermediate and advanced ESL Participants. A three-test sample of literal and figurative PVs including (multiple-choice, translation, or recall) was conducted. In addition, fifteen native speakers also took part in the multiple-choice test as a control group. It was found that intermediate learners avoided the use of PVs more than advanced learners.

Yunseong Cheon (2006) studied the lexical aspects of PVs and their semantic properties. She investigated two different conditions, namely the context and the translation learning among Arabic and Korean speakers studying English. She claimed that the use of sentence context was better to remember and keep in memory than using the translation condition. She concludes that context is necessary to retain vocabulary knowledge whereas the impact of the learning conditions was parallel to the other factors like the proficiency level, mother tongue, and test conditions. Therefore, context will carry its influence when interacted with other variables.

On how to solve the problem of the avoidance of PVs in the Chinese context Junyu Chen (2007) claimed that the avoidance of PVs often leads to poor communication. The avoidance of English PVs was clear after testing 300 subjects in a university in China. The subjects were 240 non-English major students and 60 English major students with different academic levels. The study revealed two considerable findings. First, they were not avoiding PVs on purpose but they had a relatively weak understanding of English vocabulary in general. For example, many students recognize meanings like 'fasten', 'don't include' and 'discover' but they have difficulty in identifying meanings of the PVs like 'tie up', 'leave out' or 'find out'. Furthermore, both native speakers of English and Chinese learners of English are likely to avoid using PVs when communicating in the foreign language. Since English PVs, as Junyn Chen previously assumed, are important components in communication, they need to be emphasized in English language teaching and learning.

Sarah and Mohammadreza (2013) observed avoidance of PVs among the Persian (Iranian) EFL learners. They took avoidance behavior into account taking into consideration proficiency level, test type (multiple choice, and translation), and PVs type (literal and figurative) in order to identify their relationship. The findings of their study showed that the Persian (Iranian) learners are relatively ignoring PVs at both advance and intermediate level. It is clear from previous studies that semantic complexity is the main reason for avoidance behavior by the learners since figurative PVs were largely avoided. It was concluded that proficiency level of learners is explicitly symmetrical to avoidance which means that avoidance reduction is connected with learners' increase of his or her proficiency level.

Finally, avoidance behavior of PVs is apparent among Pakistani (Urdu) ESL Learners of English as a second language (ESL). In a study conducted by Shahzad Karim,
Dur-e-Shahwar (2015) for Sixty Pakistani (Urdu) ESL participants (30 advanced and 30 intermediate) where both (Literal and Figurative) PVs and learners' proficiency level were taken into question, the findings also highlight the semantic complexity of PVs as a reason of the avoidance of PVs. Once again, there was a significant relation between avoidance behavior and proficiency level of the learners.

In conclusion, L2 learners of English suffer from semantic, interpreting and avoidance problems when are addressed by PVs either literally or figuratively during academic years of study which led to ineffective communication or avoidance behavior. Based on the previous findings, we will shed light on difficulties of interpreting English VPs for Jordanian L2 learners of English of different academic levels who study at Al-Hussein Bin Talal University. This area of language is not given much attention from faculty members or college instructors who design study plan or course syllabus. PVs seldom appear throughout translation or grammar course designed for majoring English students or even during school stages. There is a general feeling that students received limited data exposure to PVs interpretation and use through their past academic years. So, the researcher will test both non-majoring English students and majoring English students to measure their ability to interpret English VPs by using a multiple-choice test based on reading, listening test, writing test and sentence completion test. Students' scores will be analyzed taking into consideration their gender, academic year and specialization.

\section{THEORETICAL FRAMEWORK AND METHODOLOGY}

This study aims at identifying the difficulties that arise when Jordanian L2 learners of English language encounter two-part or three-part PVs in oral speech context, reading session, dialogues or written test. Even advanced college learners would be facing the problem of interpreting PVs, since multipart phrasal verbs can be combined with many prepositional phrases (i.e. find up, find out etc.,) or adverb (i.e. get together). Carl W. Hart (1999) believes that prepositions are like a substance which holds English together, but most students are unfamiliar with how or which preposition is to use.

Blau, Gonzales, and Green (1983, p. 184) divided students' problems with PVs into two categories: semantic or vocabulary problems and syntactic or word order problems. They assume that semantically, students often do not consider multi-word verb as a lexical unit that carries special meaning. This will be more evident when there is no existence of PVs in the student's first language. Students would leave the particle of the PVs out, especially when a single word in their own language can deliver the message.

Armstrong (2004) argues that teachers need to expand their knowledge of PVs and deepen perception to develop effective syntactic-designed tests through teacher training, such as the Particle Shift and Adverbial Insertion tests. Armstrong, however, classifies PVs into three semantic types: directional, aspectual, and idiomatic.

It is obvious that multi-word verbs are complex problematic both in terms of their grammatical structure and their 
lexical meaning. Various meanings, in particular, can be misleading in interpreting. Consider learners familiar with the meaning of "cut down the trees", but have problems interpreting the meaning of "cut down on packaging" (reduce). Taking this into account, we shall raise the following question: Will students be able to do better in interpreting PVs when handling teaching curricula designed to enhance learning capacity and activate interpreting and linguistic performance? One possible solution is design a special text material of useful teaching gradation to enrich students' knowledge with various meanings of PVs, translated into several languages and taught during regular schooling stages and levels.

The study is confined only to investigate Jordanian L2 learners of English at different academic level, majors, and gender. The sample of the study consisted of two subject groups: a group of intermediate students (20 male and female students of different academic majors, levels, and gender who study communication skills in English as an optional course at Al-Hussein Bin Talal University) and another group (37 male and female students who study English language and literature at Al-Hussein Bin Talal University for the academic year 2016/2017). This study is limited to students of the second, third, fourth, and fifth year. To evaluate students' capability in handling PVs interpretation, a sample of four tests was designed to examine their ability in language using multiple choices, listening to a dialogue, rewriting sentences using their own words, and interpreting PVs with different preposition throughout sentence completion.

The interpretation test was administered during students' regular class time. Students were informed about the general purpose of the study, the type of information they were required to provide (interpreting a text of a four-sample-designed test), and the importance of their contribution to the study. They were also informed that their answers would be dealt with anonymously. Participants were presented with an informed consent form to sign and a copy of the interpreting test to answer. The test distribution and collection took place during the same session, and the average time the participants spent on the task was around 55 minutes. Following data collection, the responses of each student were checked with emphasis not only on the correct responses but also on the wrong English spelling students used. One point was credited for each correct response and a zero for an incorrect one. The data was fed into (SPSS) Software linear regression for statistical analyses that was carried out using ANOVA and Coefficient ( $\mathrm{t}$ test) statistics.

\section{STATISTICAL ANALYSIS OF THE FINDINGS}

The results clarified in the tables below answer the question: Do gender, major or academic year play a vital part the skills of PVs interpretation when it comes to language use through multiple choices? As shown in Table 1 above, the value of $(F=6.791)$ and the value of significance $(0.001)$ mean that statistical differences are significant at level $(\alpha \leq 0.05)$ which indicate that the independent variables are significant and they identify the variation in the dependent variable.

The coefficient variable (academic) as shown in Table 2 is significant at level $(\alpha \leq 0.05)$ which indicates the linear relationship between the dependent and independent variables. The academic year for both groups of students affected their ability to perform better in multiple choices whereas (gender and major) are slightly significant.

By referring to the second question: How can students analyze the content of spoken texts where PVs are addressed through listening? From the ANOVA Table 3, we notice that the statistical differences are not significant at level $(\alpha \leq 0.05)$ where the value $(\mathrm{F}=1.303)$ and value of significance $(0.283)$ which means that the independent variables have a minor variation effect for the dependent variable as ( $\mathrm{R}$ square $=0.069$ ) indicating a weak relationship.

Table 4 shows that the variables indicate a slight statistical significance for both groups of students. The indepen-

Table 1. Dependent variable: Test1 (score 10)

\begin{tabular}{|c|c|c|c|c|c|c|c|}
\hline Model & Sum of squares & df & Mean square & $\mathbf{F}$ & Significance & R square & $\mathbf{R}$ \\
\hline \multicolumn{8}{|l|}{1} \\
\hline Regression & 73.044 & 3 & 24.348 & 6.791 & $0.001^{\mathrm{a}}$ & & \\
\hline Residual & 190.009 & 53 & 3.585 & & & 0.278 & $0.527^{\mathrm{a}}$ \\
\hline Total & 263.053 & 56 & & & & & \\
\hline
\end{tabular}

a. Predictors: (Constant), Academic, Gender, Major

Table 2. Coefficients ${ }^{\mathrm{a}}$

\begin{tabular}{|c|c|c|c|c|c|}
\hline \multirow[t]{2}{*}{ Model } & \multicolumn{2}{|c|}{ Unstandardized coefficients } & \multirow{2}{*}{$\begin{array}{c}\text { Standardized coefficients } \\
\text { Beta }\end{array}$} & \multirow[t]{2}{*}{$\mathbf{t}$} & \multirow[t]{2}{*}{ Significance } \\
\hline & B & Standard error & & & \\
\hline \multicolumn{6}{|l|}{1} \\
\hline (Constant) & 8.724 & 1.195 & & 7.303 & 0.000 \\
\hline Gender & -0.751 & 0.533 & -0.170 & -1.409 & 0.165 \\
\hline Major & 0.077 & 0.108 & 0.095 & 0.719 & 0.475 \\
\hline Academic & -1.038 & 0.327 & -0.414 & -3.174 & 0.003 \\
\hline
\end{tabular}

Dependent variable: Test1 (score 10) 
dent variables indicate a weak linear relationship and so are insignificant. It can be inferred that listening tasks are real negative factors that influence students' interpretation fluency.

Table 5 bleow involves an answer to the third question: What difficulties that PVs involve when L2 learners interpret from SL to TL in writing tasks? We notice that the variables show no statistical significance at level $(\alpha \leq 0.05)$ and the value $(\mathrm{F}=3.144)$ and the significance value $(0.033)$ show a weak linear relationship. Again $(\mathrm{R}$ Square $=0.151)$ appears to show no variation for dependent variable.

From table 6 below we notice that the variables for both English and non-English students were not significant at level $(\alpha \leq 0.05)$. This tell us that the vocabulary building pro- cess through the academic period of study might be a reason behind students' inability to re-write statements that involve PVs in their own words.

By analyzing statistical data of coefficients in the ANOVA (Table 7) to answer the fourth question: How do L2 students identify the meaning of PVs in sentence completion based on interpreting knowledge and linguistic performance? As we consider the value of $(\mathrm{F}=1.328)$ and the value of significance $(0.275)$ to show no statistical significance at level $(\alpha \leq 0.05)$ and so do not reflect the linearity of the relationship between the dependent and independent variables. ( $R$ square $=0.070$ ) indicates a slight variation of the variables.

From the coefficient variables in Table 8 , which are not statistically significant at level $(\alpha \leq 0.05)$, it can be

Table 3. ANOVA ${ }^{\mathrm{b}}$

\begin{tabular}{|c|c|c|c|c|c|c|c|}
\hline Model & Sum of squares & df & Mean square & $\mathbf{F}$ & Significance & R square & $\mathbf{R}$ \\
\hline \multicolumn{8}{|l|}{1} \\
\hline Regression & 8.750 & 3 & 2.917 & 1.303 & $0.283^{\mathrm{a}}$ & 0.069 & \\
\hline Residual & 118.619 & 53 & 2.238 & & & & $0.262^{\mathrm{a}}$ \\
\hline Total & 127.368 & 56 & & & & & \\
\hline
\end{tabular}

a. Predictors: (Constant), Academic, Gender, Major

b. Dependent variable: Test2 (score 5)

Table 4. Coefficients ${ }^{\mathrm{a}}$

\begin{tabular}{|c|c|c|c|c|c|}
\hline \multirow[t]{2}{*}{ Model } & \multicolumn{2}{|c|}{ Unstandardized coefficients } & \multirow{2}{*}{$\begin{array}{c}\text { Standardized coefficients } \\
\text { Beta }\end{array}$} & \multirow[t]{2}{*}{$\mathbf{t}$} & \multirow[t]{2}{*}{ Significance } \\
\hline & B & Standard error & & & \\
\hline \multicolumn{6}{|l|}{1} \\
\hline (Constant) & 2.978 & 0.944 & & 3.155 & 0.003 \\
\hline Gender & -0.630 & 0.421 & -0.205 & -1.495 & 0.141 \\
\hline Major & 0.022 & 0.085 & 0.039 & 0.258 & 0.797 \\
\hline Academic & -0.176 & 0.259 & -0.101 & -0.680 & 0.499 \\
\hline
\end{tabular}

a. Dependent variable: Test2 (score 5)

Table 5. ANOVA ${ }^{\mathrm{b}}$

\begin{tabular}{|c|c|c|c|c|c|c|c|}
\hline Model & Sum of squares & df & Mean square & $\mathbf{F}$ & Significance & R square & $\mathbf{R}$ \\
\hline \multicolumn{8}{|l|}{1} \\
\hline Regression & 22.867 & 3 & 7.622 & 3.144 & $0.033^{\mathrm{a}}$ & & \\
\hline Residual & 128.502 & 53 & 2.425 & & & 0.151 & \\
\hline Total & 151.368 & 56 & & & & & $0.389^{\mathrm{a}}$ \\
\hline
\end{tabular}

a. Predictors: (Constant), Academic, Gender, Major

b. Dependent variable: Test3 (score 5)

Table 6. Coefficients ${ }^{\mathrm{a}}$

\begin{tabular}{|c|c|c|c|c|c|}
\hline \multirow[t]{2}{*}{ Model } & \multicolumn{2}{|c|}{ Unstandardized coefficients } & \multirow{2}{*}{$\begin{array}{c}\text { Standardized coefficients } \\
\text { Beta }\end{array}$} & \multirow[t]{2}{*}{$\mathbf{t}$} & \multirow[t]{2}{*}{ Significance } \\
\hline & B & Standard error & & & \\
\hline \multicolumn{6}{|l|}{1} \\
\hline (Constant) & 3.156 & 0.982 & & 3.212 & 0.002 \\
\hline Gender & -0.404 & 0.438 & -0.121 & -0.923 & 0.360 \\
\hline Major & 0.112 & 0.088 & 0.181 & 1.269 & 0.210 \\
\hline Academic & -0.419 & 0.269 & -0.220 & -1.557 & 0.125 \\
\hline
\end{tabular}

a. Dependent variable: Test3 (score 5) 
Table 7. ANOVA ${ }^{\mathrm{b}}$

\begin{tabular}{|c|c|c|c|c|c|c|c|}
\hline Model & Sum of squares & df & Mean square & $\mathbf{F}$ & Significance & R square & $\mathbf{R}$ \\
\hline \multicolumn{8}{|l|}{1} \\
\hline Regression & 5.614 & 3 & 1.871 & 1.328 & $0.275^{\mathrm{a}}$ & 0.070 & \\
\hline Residual & 74.701 & 53 & 1.409 & & & & \\
\hline Total & 80.316 & 56 & & & & & $0.264^{\mathrm{a}}$ \\
\hline
\end{tabular}

a. Predictors: (Constant), Academic, Gender, Major

b. Dependent variable: Test4 (score 5)

Table 8. Coefficients ${ }^{\mathrm{a}}$

\begin{tabular}{|c|c|c|c|c|c|}
\hline \multirow[t]{2}{*}{ Model } & \multicolumn{2}{|c|}{ Unstandardized coefficients } & \multirow{2}{*}{$\frac{\text { Standardized coefficients }}{\text { Beta }}$} & \multirow[t]{2}{*}{$\mathbf{t}$} & \multirow[t]{2}{*}{ Significance } \\
\hline & B & Standard error & & & \\
\hline \multicolumn{6}{|l|}{1} \\
\hline (Constant) & 3.830 & 0.749 & & 5.113 & 0.000 \\
\hline Gender & 0.088 & 0.334 & 0.036 & 0.264 & 0.793 \\
\hline Major & 0.067 & 0.067 & 0.148 & 0.992 & 0.326 \\
\hline Academic & -0.238 & 0.205 & -0.172 & -1.161 & 0.251 \\
\hline
\end{tabular}

a. Dependent variable: Test4 (score 5)

inferred that sentence completion tasks where PVs are addressed are quite complicated to handle for both groups of participants and would require more advanced skills, exercise and practice. This is also an obstacle that would face teachers and course designers in both schooling stages and college.

Briefly, the results of the study revealed that students tend to overuse the simple word meaning than to address PVs directly. This lead, in most of the cases, to a wrong understanding of PVs. Students was not able to determine the equivalent interpretation in question. Students tend to employ alternative strategies in their attempts to interpret PVs either by using more simplified form of meaning or ignoring interpretation totally. The actual reasons behind general weaknesses to handle PVs meanings, and difficulty in interpreting PVs might be attributable to many years of earlier schooling avoidance by students at different levels. The total scores obtained by both groups of students participated in the study suggest that the (academic) year for students was the most significant coefficient variable, which is a factor influenced also by proficiency levels of students. For example, Junyu Chen (2007) reported findings suggesting that learners are not deliberately avoiding PVs, but they had a relatively weak understanding of the body of English vocabulary.

\section{CONCLUSIONS AND RECOMMENDATIONS}

As earlier indicated by different research findings, PVs present a challenge for language teachers and students, as evidenced by the amount of research that has been done to understand, classify, and teach them. ESL teachers are typically given knowledge of syntactic tests to identify PVs, but a deeper semantic knowledge may help them teach more effectively, Tom Gustafson \& Karen Cathcart (2015).

As VPs are essential part of the body of English vocabulary and so constitute a huge area of meaning which overlaps with hundreds of semantic-word denotations and connota- tions, they will always appear as complex units that EFL learners face even from different culture and background levels. Jordanian L2 learners of English whose mother lounge is Arabic were found unable to address the lexical meaning of VPs effectively when they were being examined. Even advanced students would, most of the time, fail to analyze and understand PVs through listening, reading, writing or speaking. The study reveals a gap that both learners and teachers have to work on and resolve in the future either by intensive class-tutorial or perfect learning environments.

However, the overall scores obtained by students in the language use test indicate the academic level of students is significant which means that language experience would reflect a better ability to interpret VPs. The listening sample test, on the other hand, show that spoken English involving VPs is the most difficult task EFL Jordanian learners would face as they do not interact with native speakers directly. Again for the third question raised previously, the task of writing using one's own words also indicate a general weakness in vocabulary building. Finally, the sentence completion test was not easy to handle by most EFL Jordanian students and reveal another learning difficulty in interpreting English PVs.

Studies indicate that some strategies may help L2 learners grasp the identification and interpretation of PVs. These strategies need to be examined further with more languages, better methodologies, and multiple levels of students to verify their effectiveness.

It is clear that learner's problem with PVs is not basically grammatical, but an obstacle that they frequently face when it comes to interpretation. Additionally, this area of language is open to different cultural-specific usage within accents, dialects and types of speech around the world such as American, British, Canadian and Australian English.

The bulkiness of PVs in dictionaries makes it rigid to be imposed on adult learners through years of academic learning of a language which is not one's own. However, if we 
agree that texts can be interpreted, then, in what way learners' strategies to capture the actual meaning of a verb plus a preposition can be self-directed, or shall they ignore the interpretation by giving a more simplified meaning based on the mother tongue? Is there a significant a learning or teaching strategy that may enable students to capture the meaning of the PVs? Through a course test, translating assignments, field work (inviting guest lectures, interviewing native or foreign speakers, and special educational programs).

In brief, the best course of action would be to include this type of VPs interpretation in teaching curricula of early schooling to get pupils exposed more to the nature of the meaning of VPs. We should also enhance adults learning by giving rich material covering VPs context, meaning and translation. English courses for majoring English students should be consistently maintained to adapt students' academic path through a careful planning of what is to be taught. This area of language is fundamental to learners' academic performance and so has to be enhanced by a variety of rich course planning and teaching curricula.

\section{REFERENCES}

Armstrong, K. (2004). Sexing up the dossier: A semantic analysis of phrasal verbs for language teachers. Language Awareness, 13(4), 213-224.

Blau, E. K., Gonzales, J. B., \& Green J. M. (1983). Helping students sort out phrasal verbs. In H. F. John (Ed.), Selected articles from the TESOL newsletter, 1986-1983 (pp. 184). Washington, DC.

Carlos Ramisch and Laurent Besacier and Alexander Kobzar (2013) How hard is it to automatically translate phrasal verbs from English to French? Proceedings of the Workshop on Multi-Word Units in Machine Translation and Translation Technology, Nice, September 3, 2013, p53-61.

Chen, J. (2007) On how to solve the problem of the avoidance of phrasal verbs in the Chinese context. International Education Journal, 8(2), 348-353

Cheon, Y. (2006). A Pilot Study in Learning English Phrasal Verbs.http://www.pdfdrive.net/apilot-study-in-learningenglish-phrasal-verbs-E6254324.html [may2 ${ }^{\text {nd }}, 2014$ ]. Accessed on November $14^{\text {th }} 2017$.
Dagut M., \& Laufer B. (1985). Avoidance of phrasal verbs-A case for contrastive analysis. Studies in Second Language Acquisition, 7, 73-79.

Fletcher, B. (2005). Register and phrasal verbs. Macmillan Phrasal Verbs Plus. Oxford: Macmillan Publishers Limited. LS 13-LS15.

HALLIDAY, M.A.K., and Hassan, R. (1976) Cohesion in English, London: Longman.

Hart, C (1999). The ultimate phrasal verb book. Hauppauge, NY: Barron's Educational Series. Library of Congress Cataloging.

Kleinmann H.H. (1977). Avoidance behavior in adult second language acquisition. Language learning, 27, 93 - 107, p 93-107.

Levenston E. A. (1971). Over- indulgence and under-representation: Aspects of mother-tongue interference. In Nickel G. (Ed.), Papers in contrastive linguistics (pp. 115-121). Cambridge: Cambridge University Press.

Liao, Y., \&Fukuya, Y. J. (2004). Avoidance of phrasal verbs: The case of Chinese learners of English. Language Learning, 54(2), 193-226.

Peter Newmark (1988) A textbook of Translation, NEW YORK, PRENTICE HALL.

Ramisch, C., Besacier, L, \& Kobzar, O. (2013) How hard is it to automatically translate phrasal verbs from English to French? In: Mitkov R, Monti J, Pastor GC, Seretan V (eds) Proceedings of the MT summit 2013 workshop on multi-word units in machine translation and translation technology (MUMTTT 2013), Nice, pp 53-61.

Sara, H., \& Mohammadreza, T. (2013). Study on avoidance behavior among Persian EFL learners: Phrasal verbs in focus. Greener Journal of Educational Research, 3(6), 238-248.

Shahzad Karim, D. (2015) Avoidance of English Phrasal Verbs: A Study Based on the Pakistani ESL Learners. ELF Annual Research Journal 17, p125-144.

Sinclair, J. (1989). Collins COBUILD Dictionary of Phrasal Verbs. Collins COBUILD, London, UK. 512 p.

T. G., \& Karen, C. (2015). The Acquisition of Phrasal Verbs in L2 English: A Literature Review, Linguistic Portfolios, Vol. 4, Art. 8, p 92-99. 